\title{
PEMBERIAN AMELIORAN PADA TAILING UNTUK MENINGKATKAN PERTUMBUIHAN KEMIRI (Alaurites moluccana (L) Wild DI PERSEMAIAN
}

\author{
Giving Ameliorant On Tailing For Growth Aleurites moluccana (L.) Willd At Nursery
}

\section{Gustian, Burhanuddin, Wiwik Ekyastuti}

Fakultas Kehutanan Universitas Tanjungpura. Jalan Daya Nasional Pontianak 79124

Email : gustian.borneo@yahoo.com

\begin{abstract}
Gold mining activities have negatively impacted post-mining land into poor nutrients, low pH, toxic soil, due to heavy metal content, low water holding capacity, low organic matter content and unstable land conditions. To change the tailings to be more productive many of the available technologies, such as the use of manure, compost, litter or the use of soil microbes such as mycorrhiza. The addition of manure can additionally increase nutrient available, can also improve the physical and biological properties of the soil. Alaurites moluccana $(L)$ Wild) is one of the plants classified as a pioneer species because it can grow on critical land with low soil fertility and open soil. Research on ameliorant of tailings to increase the growth of A. moluccana in the nursery aims to obtain a mixture of ameliorants with the tailings to enhance the growth of A. moluccana in the nursery. Treatment was given to the growth of seedlings of A. moluccana using the Completely Randomized Design (RAL) exprotment method with a total of 8 treatments that included an ameliorant tailing control, tailings with ameliorant a (1: 1, 1:2, and 1: 3), tailings with ameliorant $b(1: 1,1: 2$, and 1:3) and ultisol soil control, with each treatment repeated 5 times. Data collected were shoot hight $(\mathrm{cm})$, stem diameter $(\mathrm{mm})$, number of leaves and dry weight of plant. The result of tailings treatment with addition of organic ameliorant gave a very significant effect on the growth of height, diameter, number of leaves and dry weight of the A. Moluccana. The best media treatment for all parameters is $M_{6}$ (tailings: kotoran sapi 1: 3 ). Although virtually all treatments with organic ameliorant provide better results than controls without the addition of organic ameliorants.

Keywords: Tailings, ameliorant, A. moluccana, organic.
\end{abstract}

\section{PENDAHULUAN}

Jumlah penambangan emas rakyat saat ini di Indonesia, diperkirakan telah mencapai 713 titik yang tersebar di beberapa wilayah seperti Jawa, Sumatra, Kalimantan, Sulawesi dan Nusa Tenggara (Aspinall, 2001). Diperkiran jumlah ini terus bertambah seiring dengan pertambahan penduduk, termasuk luasan tambang emas tanpa izin (PETI) di Kalimantan Barat. Berdasakan laporan dari Badan Pusat Satistik Provinsi Kalimantan Barat
(2015), luasan PETI di setiap Kabupaten antara 3000-6000 ha.

Aktivitas penambangan emas telah menimbulkan dampak negatif yaitu lahan pascatambang menjadi miskin hara, nilai $\mathrm{pH}$ rendah, tanah bersifat toksik, karena kandungan logam berat, kapasitas menahan air rendah, kandungan bahan organik rendah dan kondisi lahan tidak stabil (Ambardini, 2014). Pada umumnya, tailing bersifat porositas tinggi sehingga kapasitas memengang air (holding capacity) rendah, struktur tidak stabil, sangat 
miskin bahan organik, miskin unsur hara makro dan mikro, aktivitas mikroba juga tidak terdeteksi sehingga memerlukan waktu yang relatif lama dan strategi tertentu untuk mengelolanya menjadi lahan yang lebih produktif (Kartosujono, 1994).

Untuk merubah tailing menjadi lebih produktif banyak teknologi yang tersedia, antara lain penggunaan pupuk kandang, kompos, seresah atau penggunaan mikroba tanah seperti mikoriza (Rahmawaty, 2002). Tujuan memberikan pupuk organik (pupuk kandang atau pupuk hijau) untuk memperbaiki sifat fisik, kimia dan biologi tanah. Kombinasi penggunaan kompos dalam memulihkan tailing sangat epektif dalam menentukan dan menjaga daya penutupan vegetasi dan produksi biomassa serta mengurangi menyerapan logam berat oleh tanaman. Pemulihan yang lebih cepat diperlukan untuk mengimbangi kecepatan produksi tailing itu sendiri atau kerusakan lingkungan yang semakin parah salah satunya dengan tanaman kemiri

Tanaman kemiri (Aleurites molucanna (L.) Willd) telah banyak dikembangkan di Indonesia, baik sebagai tanaman perkarangan maupun sebagai tanaman reboisasi untuk tujuan konservasi dan perbaikan lingkungan (Direktorat Jenderal Perkebunan Departemen Pertanian, 2006). Kemiri umumnya ditanam sebagai penahan angin, pembatas, penaung, stabilisator tanah dan pengisi lahan - lahan kosong (Krisnawati et al. 2011). Kemiri dapat tumbuh pada tanah agak asam sampai basa ( $\mathrm{pH} 5-8)$, ekstrak minyak kemiri dapat dibuat sabun, di industri kosmetik telah dijual secara luas dan dapat dijadikan produk komersial utama, sisa ekstrak biji dapat digunakan untuk pupuk dan dengan memodifikasi secara kimia, minyak dapat dijadikan bahan bakar untuk mesin diesel (Elevitch dan Manner, 2006). Kemiri merupakan salah satu tanaman yang digolongkan sebagai jenis pioner karena dapat tumbuh pada lahan kritis dengan tingkat kesuburan tanah rendah dan tanahnya terbuka (Hendromono et al. 2005). Biji tanaman kemiri memiliki kulit biji yang keras dan impermiabel (resisten terhadap $\mathrm{O}_{2}$ dan air) menyebabkan benih kemiri menjadi dorman (istirahat), sehingga sulit mendapatkan bibit yang tumbuh serempak dalam jumlah banyak. Benih kemiri membutuhkan waktu yang lama untuk berkecambah. Kemampuan berkecambah benih kemiri umumnya sekitar $80 \%$ dalam waktu 4-6 bulan (Husain dan Tuiyo, 2012). Menurut Udarno et al. (1990) menyatakan waktu berkecambah kemiri dapat mencapai 2 bulan. Jika diberi perlakuan dengan peretakan dapat mempercepat proses perkecambahan menjadi 15-20 hari saja.

Penelitian ini mendukung restorasi lahan pascatambang emas perlu dilakukan dengan menggunakan tanaman produktif. Sehingga penelitian dapat menjawab permasalahan lingkungan yang timbul akibat industri pertambangan sekaligus dapat meningkatkan ekonomi dari segi pemanfaatan tanaman. Oleh karena itu restorasi tailing menggunakan tamanan kemiri dengan memanfaatkan amelioran perlu dilakukan penelitian atau kajian. 
Penelitian ini dilaksanakan atas dasar memperbaiki lahan bekas tambang yaitu tailing dengan perlakuan penambahan amelioran berupa pupuk organik dari kompos dan kotoran sapi. Perlakuan tersebut ialah dengan pencampuran antara media taling dengan amelioran dipersemaian dengan beberapa perlakuan untuk mendapatkan hasil yang terbaik. Diduga dengan adanya pencampuran jenis amelioran pada tailing akan memberikan pertumbuhan tanaman kemiri terbaik yang nantinya akan berkontribusi dalam memperbaiki lahan bekas tambang.

\section{METODELOGI PENELITIAN}

Penelitian ini dilaksanakan selama 6 bulan, terdiri dari penelitian pengujian perkecambahan biji kemiri dan pengujian perbaikan media tailing dengan penambahan amelioran. Penelitian dilaksanakan di rumah plastik Laboratorium Silvikultur Fakultas Kehutanan Universitas Tanjungpura Pontianak.
Perlakuan yang diberikan terhadap pertumbuhan bibit kemiri menggunakan metode exprimen Rancangan Acak Lengkap (RAL). Perlakuan sebanyak 8 yang mencakup kontrol tailing tanpa amelioran, tailing dengan amelioran a (1:1, 1:2, dan 1:3), tailing dengan amelioran b (1:1, 1:2, dan 1:3) dan kontrol tanah ultisol, dengan masingmasing perlakuan diulang sebanyak 5 kali. Data yang dikumpulkan berupa tinggi bibit $(\mathrm{cm})$, diameter bibit $(\mathrm{mm})$, jumlah daun (helai) dan bobot kering tanaman. Seluruh data akan dianalisis menggunakan softward SAS IX.

Berdasarkan perhitungan analisis keragaman, maka nilai F.Hit $>$ dari Sig. $0,000(0,05 \%$ pada tarif uji $5 \%)$ berarti berpengaruh nyata. Perlakuan yang berpengaruh nyata dan sangat nyata selanjutnya dilakukan uji berganda Duncan atau deda nyata jujur (Gespersz, 1991)

\section{HASIL DAN PEMBAHASAN}

Pengaruh media terhadap pertumbuhan kemiri

Tabel 1. Rekapitulasi sidik ragam pengaruh macam media terhadap pertumbuhan semai kemiri di persemaian (Recapitulation of effect from media for the growth of $A$. moluccana in the nursery).

\begin{tabular}{lcccc}
\hline Perlakuan & $\begin{array}{c}\text { Pertumbuhan } \\
\text { Tinggi }(\mathbf{c m})\end{array}$ & $\begin{array}{c}\text { Peretumbuhan } \\
\text { Diameter }(\mathbf{m m})\end{array}$ & $\begin{array}{c}\text { Pertumbuhan } \\
\text { Jumlah daun } \\
(\text { helai) }\end{array}$ & $\begin{array}{c}\text { Berat kering } \\
\text { tanaman }(\mathbf{g})\end{array}$ \\
\hline Media $(\mathbf{M})$ & $* *$ & $* *$ & $* *$ & $* *$ \\
\hline Galat & - & - & - & - \\
\hline Faktor koreksi & $\mathbf{1 2 , 4 5}$ & $\mathbf{1 5 , 6 9}$ & $\mathbf{1 5 , 3 0}$ & $\mathbf{3 3 , 8 3}$ \\
\hline Keterangan & $* *=$ sangat nyata $(\leq 0,01)$ \\
$*$ & $=$ nyata $(0,01 \leq \mathrm{p} \leq 0,05)$ \\
tn & $=$ tidak nyata $(\mathrm{p} \geq 0,05)$ & & & \\
\end{tabular}

Hasil sidik ragam menunjukkan bahwa perlakuan media semai memberikan pengaruh yang sangat nyata terhadap semua parameter yang diamati yaitu tinggi semai kemiri, diameter semai kemiri, jumlah daun semai kemiri dan berat kering semai kemiri (Tabel 1). 
Oleh karena itu semua parameter yang diamati dilakukan uji lanjut.

\section{Tinggi semai kemiri}

Pertumbuhan tinggi semai kemiri pada umur 3 bulan setelah penyapihan (Gambar 1) menunjukan perbedaan yang nyata pada jenis media $\mathrm{M}_{3}$ (tailing dan kompos 1:3), $\mathrm{M}_{5}$ (tailing dan kotoran sapi 1:2) dan $\mathrm{M}_{6}$ (taling dan kotoran sapi 1:3) dibandingkan dengan tanaman kontrol. Peningkatan pertumbuhan tinggi semai kemiri pada masing - masing jenis media $\mathrm{M}_{3}$ (tailing dan kompos 1:3), $\mathbf{M}_{5}$ (tailing dan kotoran sapi 1:2) dan $\mathbf{M}_{6}$ (taling dan kotoran sapi 1:3) berturut - turut sebesar $84,43 \%$, 94,61 \% dan $102,40 \%$ dibandingkan dengan kontrol. Nismawati et al. (2013) menyebutkan bahwa hasil sidik ragam menunjukan pemberia bokashi berpengaruh sangat nyata terhadap pertumbuhan tinggi semai kemiri.

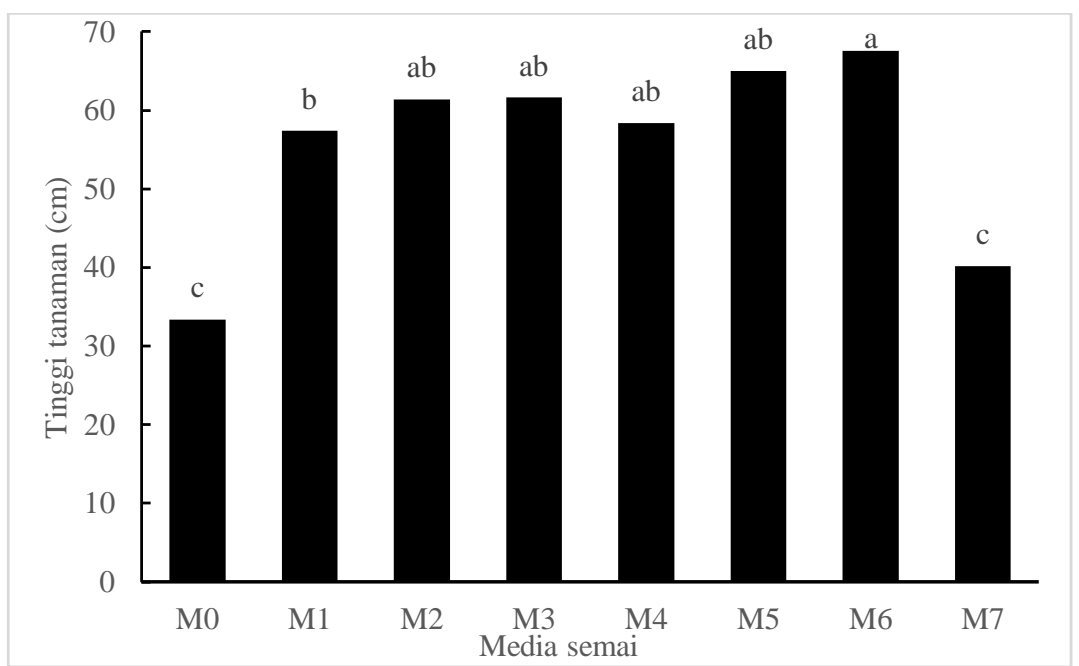

Gambar 1. Pengaruh jenis media semai terhadap tinggi tanaman kemiri umur 3 bulan setelah sapih (Effect of media to shoot height of $A$. moluccana at 3 months after weaning).

Keterangan: Huruf yang sama pada histogram tidak berbeda nyata berdasarkan uji jarak berganda Duncan taraf $5 \%, \mathrm{M}_{0}=$ tailing (kontrol), $\mathrm{M} 1=$ tailing dan kompos 1:1, $\mathrm{M}_{2}=$ tailing dan kompos 1:2, $\mathrm{M}_{3}=$ tailing dan kompos 1:3, $\mathrm{M}_{4}=$ tailing dan kotoran sapi 1:1, $\mathrm{M}_{5}$ $=$ tailing dan kotoran sapi 1:2, $\mathbf{M}_{6}=$ tailing dan kotoran sapi 1:3 dan $\mathbf{M}_{7}=\operatorname{tanah}$ ultisol (kontrol).

Hasil penelitian ini sesuai dengan hasil yang diperoleh Sufardi et al. (2013) bahwa penggunaan amelioran pupuk kotoran sapi dapat meningkatkan pertumbuhan tanaman jagung sebesar $120 \%$ dibandingkan tanaman kontrol pada tanah Andisol. Peningkatan pertumbuhan tinggi tanaman kemiri yang diamati pada umur 3 bulan setelah sapih terbukti dipengaruhi oleh pemberian amelioran organik kotoran sapi. Hal ini menunjukan bahwa pupuk kandang kotoran sapi dapat meransang pertumbuhan tanaman kemiri lebih cepat. Peningkatan tinggi tanaman kemiri akibat pemberian amelioran kotoran sapi disebabkan karena bahan organik kotoran sapi mengandung 
sejumlah hara dan bahan organik tersebut dapat memperbaiki sifat fisik kimia dan biologi tanah.

\section{Diameter semai kemiri}

Pertumbuhan diameter semai kemiri pada umur 3 bulan setelah penyapihan (Gambar 2) menunjukan perbedaan yang nyata pada jenis media $\mathrm{M}_{1}$ (taling dan kompos 1:1), $\mathrm{M}_{5}$ (tailing dan kotoran sapi 1: 2) dan $\mathbf{M}_{6}$ (tailing dan kotoran sapi 1:3) dibandingkan dengan tanaman kontrol. Peningkatan pertumbuhan diameter semai kemiri pada masing - masing jenis media $\mathbf{M}_{1}$ (tailing dan kompos 1:1), $\mathrm{M}_{5}$ (tailing dan kotoran sapi 1:2) dan $\mathbf{M}_{6}$ (taling dan kotoran sapi 1:3) berturut - turut sebesar 20,17\%, 42,83 $\%$ dan 49,32 \% dibandingkan dengan kontrol. Hasil penelitian ini didukung oleh hasil penelitian Lesmanawati (2012) dengan penambahan pupuk organik kompos pada tailing sebanyak $15 \%$ - $20 \%$ dapat meningkatakan pertambahan diameter gmelina dan sengon.

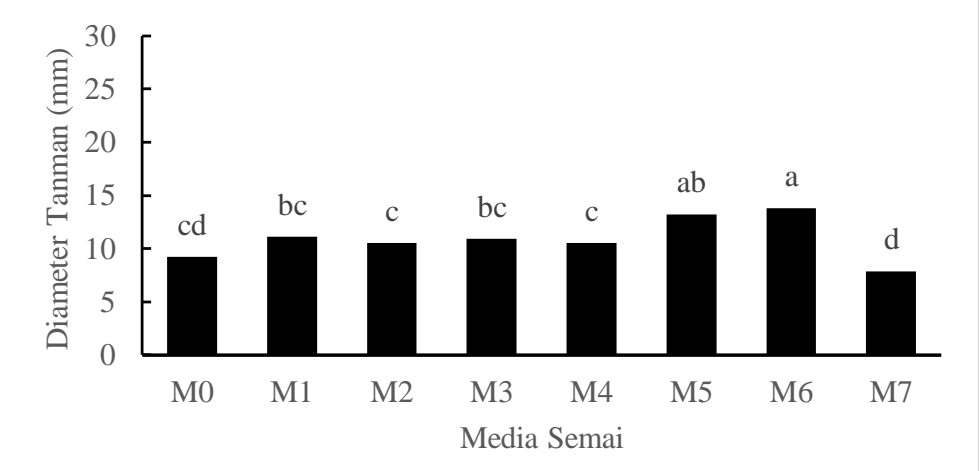

Gambar 2. Pengaruh jenis media semai terhadap diameter tanaman kemiri umur 3 bulan setelah sapih sapih (Effect of media to stem diameters of A. moluccana at 3 months after weaning).

Keterangan: Huruf yang sama pada histogram tidak berbeda nyata berdasarkan uji jarak berganda Duncan taraf $5 \%, \mathrm{M}_{0}=$ tailing (kontrol), $\mathrm{M}_{1}=$ tailing dan kompos 1:1, $\mathrm{M}_{2}=$ tailing dan kompos 1:2, $\mathrm{M}_{3}=$ tailing dan kompos 1:3, $\mathrm{M}_{4}=$ tailing dan kotoran sapi 1:1, $\mathrm{M}_{5}$ = tailing dan kotoran sapi 1:2, $\mathbf{M}_{6}=$ tailing dan kotoran sapi 1:3 dan $\mathbf{M}_{7}=$ tanah ultisol (kontrol).

\section{Jumlah daun semai kemiri}

Pertumbuhan jumlah daun semai kemiri pada umur 3 bulan setelah penyapihan (Gambar 3) menunjukan perbedaan yang nyata pada jenis media $\mathrm{M}_{5}$ (tailing dan kotoran sapi 1:2), $\mathrm{M}_{3}$ (taling dan kompos 1:3) dan $\mathbf{M}_{6}$ (taling dan kotoran sapi 1:3) dibandingkan dengan tanaman kontrol. Peningkatan pertumbuhan jumlah daun semai kemiri pada masing - masing jenis media $\mathrm{M}_{5}$ (tailing dan kotoran sapi 1:2), $\mathrm{M}_{3}$ (taling dan kompos 1:3) dan $\mathbf{M}_{6}$ (taling dan kotoran sapi 1:3) berturut - turut sebesar $84,85 \%, 90,91 \%$ dan 139,39\% dibandingkan dengan kontrol. Demikian juga hasil yang disampaikan Wiralaga et al. (2011) bahwa penambahan bahan organik kompos tandan kosong kelapa sawit lebih tinggi dari dua bahan organik kotoran ayam dan kompos sampah kota 
JURNAL TENGKAWANG (2017)

Vol. 7 (2) : 63 - 72

pada tailing dalam meningkatkan

pertumbuhan tanaman karet.

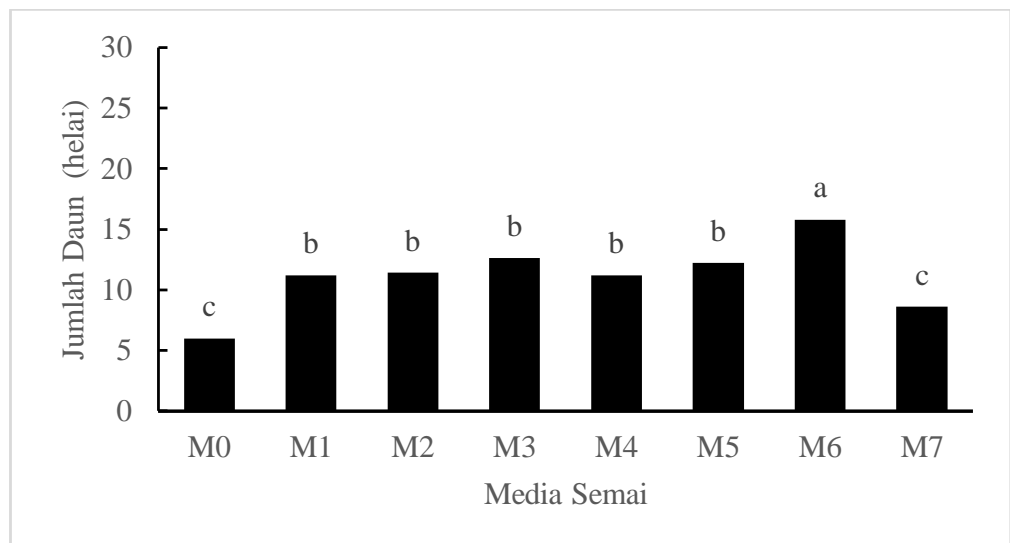

Gambar 3. Pengaruh jenis media semai terhadap jumlah daun kemiri umur 3 bulan setelah sapih sapih (Effect of media to number of leaves of $A$. moluccana at 3 months after weaning).

Keterangan: Huruf yang sama pada histogram tidak berbeda nyata berdasarkan uji jarak berganda Duncan taraf $5 \%, \mathrm{M}_{0}=$ tailing (kontrol), $\mathrm{M}_{1}=$ tailing dan kompos 1:1, $\mathrm{M}_{2}=$ tailing dan kompos 1:2, $\mathbf{M}_{3}=$ tailing dan kompos 1:3, $\mathbf{M}_{4}=$ tailing dan kotoran sapi 1:1, $\mathrm{M}_{5}$ $=$ tailing dan kotoran sapi 1:2, $\mathbf{M}_{6}=$ tailing dan kotoran sapi 1:3 dan $\mathbf{M}_{7}=\operatorname{tanah}$ ultisol (kontrol).

\section{Berat kering semai kemiri}

Berat kering semai kemiri pada umur 3 bulan (Gambar 4) menunjukan perbedaan yang nyata pada jenis media $\mathrm{M}_{5}$ (tailing dan kotoran sapi 1:2), $\mathrm{M}_{3}$ (tailing dan kompos 1:3) dan $\mathrm{M}_{6}$ (taling dan kotoran sapi 1:3) dibandingkan dengan tanaman kontrol. Peningkatan berat kering semai kemiri pada masing masing jenis media $\mathrm{M}_{5}$ (tailing dan kotoran sapi 1:2), $\mathrm{M}_{3}$ (tailing dan kompos 1:3) dan $\mathbf{M}_{6}$ (taling dan kotoran sapi 1:3 berturut - turut sebesar 271,72 \%, 302,29 $\%$ dan 406,40 \% dibandingkan dengan kontrol. Hasil penelitian ini sesuai dengan hasil yang disampaikan Ambardini (2014) bahwa berat kering tanaman jambu mete yang di tanam pada tailing dengan penambahan pupuk organik kotoran sapi 15 gram terbaik. 


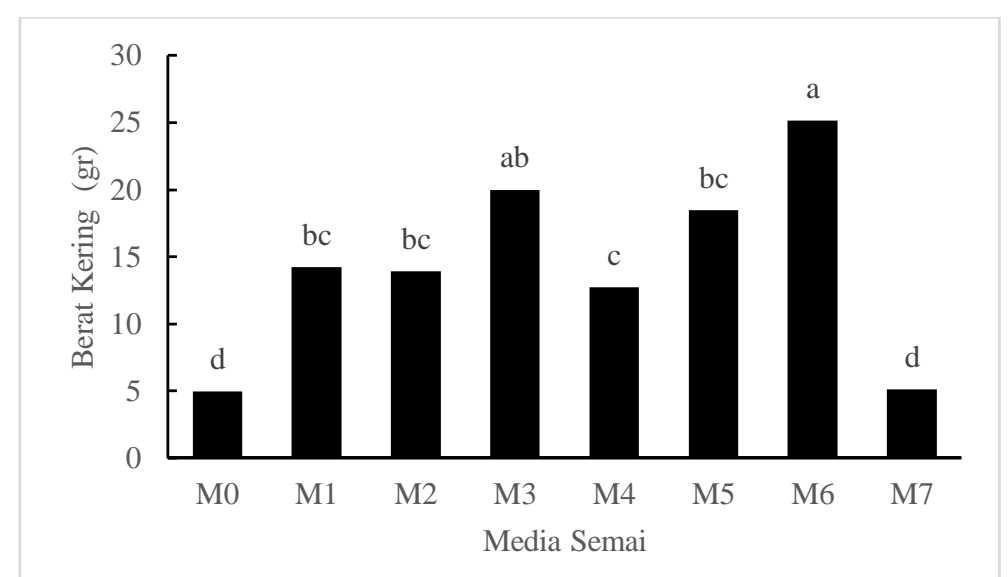

\section{Gambar 4. Pengaruh jenis media semai terhadap berat kering tanaman kemiri umur 3 bulan setelah sapih sapih (Effect of media to dry weight of $\boldsymbol{A}$. moluccana at 3 months after weaning).}

Keterangan: Huruf yang sama pada histogram tidak berbeda nyata berdasarkan uji jarak berganda Duncan taraf $5 \%, \mathrm{M}_{0}=$ tailing (kontrol), $\mathrm{M}_{1}=$ tailing dan kompos $1: 1, \mathrm{M}_{2}=$ tailing dan kompos 1:2, $\mathrm{M}_{3}=$ tailing dan kompos 1:3, $\mathrm{M}_{4}=$ tailing dan kotoran sapi 1:1, $\mathrm{M}_{5}$ $=$ tailing dan kotoran sapi 1:2, $\mathbf{M}_{6}=$ tailing dan kotoran sapi 1:3 dan $\mathbf{M}_{7}=\operatorname{tanah}$ ultisol (kontrol).

Hasil percobaan perlakuan perbaiakan tailing dengan penambahan amelioran organik memberikan pengaruh yang sangat nyata terhadap pertumbuhan tinggi, diameter, jumlah daun dan berat kering tanaman kemiri. Perlakuan media terbaik untuk semua parameter adalah $\mathrm{M}_{6}$ (tailing: kotoran sapi 1:3). Walaupun pada dasarnya hampir semua perlakuan dengan pemberian amelioran organik memberikan hasil yang lebih baik dibandingkan kontrol tanpa penambahan amelioran organik.

Hasil penelitian Soverda et al. (2008) menjelaskan bahwa pupuk organik adalah bahan yang ditambahkan ke dalam tanah untuk meningkatkan pertumbuhan tanaman. Pupuk organik memiliki banyak kelebihan dibandingkan dengan penggunaan pupuk anorganik, pupuk organik selain menambah unsur hara yang lengkap pada tanaman dapat pula memperbaiki sifat fisik, kimia dan biologi tanah, dengan memperbaiki struktur tanah, meningkatkan kapasitas tukar kation (KTK), menambah kemampuan tanah menahan air serta meningkatkan aktivitas mikroorganisme tanah. Lebih lanjut dijelaskan Kuruseng (2012), mengemukakan bahwa sumbangan bahan organik terhadap pertumbuhan tanaman merupakan pengaruhnya terhadap sifat-sifat fisik, kimia dan biologis dari tanah. Bahan organik memiliki peranan kimia dalam menyediakan unsur hara makro dan mikro untuk pertumbuhan tanaman.

Peranan biologis adalah mempengaruhi aktivitas organisme tanah, dan peranan fisiknya adalah memperbaiki struktur tanah dan daya menahan air yang baik. Media tanam yang baik harus memiliki sifat fisik yang baik, aerasi dan darinase baik serta 
kelembaban tanah harus tetap terjaga. Keseimbangan antara udara dengan kelembaban tanah berpengaruh penting terhadap pertumbuhan akar.

Tanah tailing berpotensi menurunkan tingkat kesuburan tanah dan menyebabkan keracunan bagi tanaman sehingga sulit bagi tanaman untuk tumbuh. Sebagai media tumbuh tanaman bahan tailing mempunyai banyak kendala baik fisik maupun kimia. Secara fisik bahan tailing relatif bertekstur kasar, berbutir tunggal tidak membentuk agregat seperti tanah, akibatnya daya menahan air sangat rendah. Secara kimia, bahan tailing tidak mengandung koloid sama sekali, akibatnya kapasitas tukar kation (KTK) sangat rendah, kandungan unsur hara rendah, kemampuan menahan hara juga rendah dan minim bahan organik. Kondisi ini menyebabkan aktivitas mikroorganisme menjadi rendah. Media tanah tailing yang dicampur dengan ameliorant organik kotoran sapi perbandingan 1:3 merupakan media yang mampu memberikan respon pertumbuhan kemiri terbaik di persemaian. Hal ini disebabkan dengan penambahan amelioran organik kotoran sapi pada tanah tailing dapat meningkatkan aktivitas mikroorganisme tanah dalam proses mineralisasi atau penambahan bahan organik. Karena pengaruh mineralisasi bahan organik oleh mikroorganisme secara sempurna maka pada media tanah kandungan hara menjadi meningkat terutama hara $\mathrm{N}, \mathrm{P}$ dan $\mathrm{K}$, terjadi peningkatan kapasitas tukar kation (KTK) media tanah karena memiliki daya serap kation yang lebih besar. Semakin tinggi kandungan bahan organik maka semakin tinggi KTK, sehingga $\mathrm{Fe}^{+3}$ berubah menjadi $\mathrm{Fe}^{+2}$ yang lebih tersedia bagi tanaman dan memiliki fungsi penting dalam sistem enzim dan diperlukan dalam sintesa klorofil (Hakim et al. 1986).

\section{KESIMPULAN}

Hasil penelitian membuktikan bahwa penambahan amelioran kotoran sapi atau kompos pada tailing meningkatkan pertumbuhan semai kemiri dipersemaian. Perlakuan penambahan amelioran kotoran sapi pada tailing dengan perbandingan 3:1 merupakan perlakuan yang terbaik. Produksi bibit kemiri untuk kegiatan restorasi tailing disarankan dalam proses perkecambahan dilakukan dengan peretakan dan untuk pembibitan gunakan media campuran antara tailing dengan kotoran sapi perbandingan 1:3, 1:2 atau dengan kompos perbandingan 1:3. Perlu penelitian lanjutan dilapangan untuk menguji penambahan amelioran pada tailing menggunakan tanaman kemiri.

\section{DAFTAR PUSTAKA}

Ambardini S. 2014. Biomassa Bibit Tanaman Jambu Mete (Anacardium occidentale L.) yang di Tanaman pada Tanah Pascatambang Emas Bombana dengan Pariasi Pupuk Kandang. Jurnal. Biologi: (7). 2 : $74-82$.

Aspinall C. 2001. Small-scale mining in Indonesia. International Institute for Environment and Development and the World Business Council for Sustainable Development. England. 
Badan Pusat Statistik Provinsi Kalimantan Barat. 2015. Kalimanatan Barat Dalam Angka. Katalog BPS: 1102001.61. Pontianak.

Direktorat Jenderal Perkebunan. 2006. Pedoman Budidaya Kemiri (Aleurites moluccana (L.)Willd.). Departemen Pertanian, Jakarta, Indonesia. [1 Juli 2016].

Elevitch C.R, dan Manner H.I. 2006. Traditional Tree Initiative : Species Profiles for Pacific Island Agroforestry. http://www.agroforestry.net/tti/ Alaurites-kukui.pdf [1 Juli 2016].

Gasperzs V, Teknik Analisis Dalam Penelitian Percobaan 1, Tarsito Bandung, 1991.

Hakim N, Nyakpu M.Y, Lubis A.M, Nugroho S.G, diha M.A, Hong G.B dan Bailey H.H. 1986. DasarDasar Ilmu Tanah. Universitas Lampung. Lampung.

Hendromono, Daryono, H. dan Durahim. 2005. Pemilihan Jenis Pohon untuk Rehabilitasi Lahan Kritis. Prosiding Ekspose Hasil Litbang Hutan dan Konservasi Alam. Hal : 24-31.

Husain J dan Tuiyo R. 2012. Pematahan Dormansi Benih Kemiri (Aleurites moluccana Willd) yang di Rendam Dengan Zat Pengatur Tumbuh Organik Basmingro dan Pengaruhnya Terhadap Viabilitas Benih. Jur JATT. Vol. 1 (2): 95100.

Kartosujono W. 1994. Lingkungan Pertambangan dan Reklamasi. Jakarta: Direktorat Pertambangan Umum, Departemen Pertambang dan Energi Republik Indonesia.
Krisnawati H, Kallio M dan Kanninen M. 2011. Aleurites moluccana Willd : Ekologi, Silvikultur dan Produktivitas. CIFOR. Bogor.

Kuruseng A.M. 2012. Efek REsidu Terhadap Pertumbuhan dan Produksi Tanaman Sawi. Jurusan Pertanian STTP Gowa.

Lesmanawati I.R. 2012. Respon Pertumbuhan Tanaman Gmelina Arborea Roab dan Parasianthes Jalcaturia L. Nielsen dengan Penggunaan Thiobacillus Thioparus dan Kompos dalam Upaya Biodegredasi Siamida yang Terkandung dalam tailing Emas. Jur. Sciential Education 1 (1) : 26 $-39$.

Nismawati, Wulandari R dan Irmasari. 2013. Pengaruh Pemberian Bokashi terhadap Pertumbuhan Semai Kemiri (Alaurites moluccana (L.) Willd). Jur. Warta Rimba Vol 1 No 1. Sulawesi Tanggerang.

Rahmawaty. 2002. Restorasi lahan Bekas Tambang Berdasarkan Kaidah Ekologi. Journal USU digital Library.

Soverda N, Rinaldi dan Susanti I. 2008. Pengaruh Beberapa MAcam Bokashi Terhadap Pertumbuhan dan Hasil Tanaman Tomat. Budidaya Pertanian Universitas Jambi.

Sufardi, Syakur dan Karnilawati. 2013. Amelioran Organik dan Mikoriza Meningkatkan Status Fosfat Tanah dan Hasil Jagung pada Tanah Andisol. Universitas Syiah Kuala. Jur.

Udarno R M L, Hasanal M dan Sutarno H. 1990. Pengaruh Beberapa Perlakuan Fisik dan Kimiawi 
JURNAL TENGKAWANG (2017)

Vol. 7 (2) : 63 - 72

Terhadap Daya Kecambah Benih Kemiri dan Vigor Bibit Kemiri. Jur. Bul Littro. V (2) : 92-100.

Wiralaga A.Y.A, Inonu I, Budianta D, Harun M.U, dan Yakup. 2011.
Amelioran Bahan Organik pada Media Tailing Pasir Pascatambang Timah untuk Pertumbuhan Bibit Karet. Jur. Agrotropika. Palembang. 